\title{
DISCRIMINATION OF INTRAVASCULAR LUMEN AND DISSECTIONS IN SINGLE INTRAVASCULAR ULTRASOUND IMAGES USING SUBTRACTION, CONVENTIONAL AVERAGING AND SALINE FLUSH
}

\author{
Gerard Pasterkamp, ${ }^{\dagger}$ Maurits S. van der Heiden, ${ }^{\dagger}$ Mark J. Post ${ }^{\dagger}$ \\ Cornelius Borst, ${ }^{\dagger}$ Elma J. Gussenhoven, ${ }^{\ddagger}$ Herman Pieterman, ${ }^{\ddagger}$ \\ HERo VAN URK ${ }^{\ddagger}$ and NICOLAAS BOM ${ }^{\ddagger}$ \\ ${ }^{\dagger}$ Heart Lung Institute, Utrecht University Hospital, Utrecht, The Netherlands; ${ }^{\ddagger}$ Erasmus University, Rotterdam: \\ and Interuniversity Cardiology Institute, Utrecht, The Netherlands
}

(Received 19 April 1994; in final form 10 June 1994)

\begin{abstract}
With current 30-MHz intravascular ultrasound systems, flowing blood may cause considerable backscatter which in real-time images is characterized by dynamic speckle. However, in a single intravascular ultrasound image (still-frame) the discrimination between arterial lumen and wall may be difficult due to the frozen intraluminal speckle, particularly in the presence of dissections. We compared subtraction, averaging and saline flush as methods to improve the discrimination between arterial lumen and wall in a single image. The real-time images served as gold standard. In 22 patients who underwent peripheral balloon angioplasty, ultrasound images obtained from 84 sites were examined. The sensitivity and specificity of detecting dissections were in the subtraction image $85 \%$ and $100 \%$, in the averaged image $57 \%$ and $96 \%$, and in the saline flush image $58 \%$ and $86 \%$, respectively. Subtraction is a promising method to outline the irregular lumen in a single image.
\end{abstract}

Key Words: Arteries, Balloon angioplasty, Atherosclerosis, Ultrasound.

\section{INTRODUCTION}

At present, most intravascular ultrasound systems use 20to $-30-\mathrm{MHz}$ ultrasound transducers (The et al. 1992; Pasterkamp et al. 1993; Yock et al. 1991; Davidson et al. 1991; Coy et al. 1992; Tobis et al. 1989; Isner et al. 1991). At 30 to $50 \mathrm{MHz}$, however, a better resolution of the arterial wall is obtained. Unfortunately, already at $30-\mathrm{MH} / \mathrm{z}$ intravascular ultrasound the red blood cells may act as scatterers and produce a backscatter intensity comparable to that of the vessel wall (The et al. 1992). Therefore, in a single image obtained at 30 to $50 \mathrm{MIJ}$, the frozen speckle pattern may hamper discrimination between lumen and arterial wall, and disscctions may be hard to identify. In the real-time images, on the other hand, the red blood cells appear as a dynamic speckle pattern which may be used to demarcate the intravascular lumen from the arterial wall. For off-line quantitative and qualitative analysis, however, the still-frames are used. A saline flush can be used to facilitate visualization of the irregular lumen after

Address correspondence to: Prof. Cornelius Borst, M.D., Ph.D., Heart Lung Institute, Utrecht University Hospital, Heidelberglaan 100, 3584CX Utrecht, The Netherlands. balloon dilatation in single ultrasound images (The et al. 1992), but the excessive use of saline is time consuming and potentially harmful for the patient.

Recently we reported, in a technical note (Pasterkamp et al. 1993), a method to turn the confounding backscatter of blood into an advantage. By subtracting subsequent images, flowing blood acts as contrast medium in the ultrasound image. The aim of the present study was to compare image subtraction, conventional averaging and saline flush as methods to yield a single intravascular ultrasound image with an improved demarcation of the intravascular lumen, dissections and plaque fractures. The subtraction and averaging methods were applied to intravascular ultrasound images obtained at 84 sites in the superficial femoral artery of 22 patients before and/or after balloon angioplasty. Among the intravascular ultrasound images, the real-time images served as gold standard.

\section{METHODS}

\section{Intravascular ultrasound investigation}

A 30-MHz ultrasound transducer was used, which rotated up to 16 times per second within a $5 \mathrm{~F}$ catheter 
(Du-MED, Rotterdam, The Netherlands). The axial resolution of the system was $0.1 \mathrm{~mm}$. The resulting images were displayed on a monitor via a videoscanned memory and recorded on VHS video-tape.

\section{Clinical study}

Twenty-two patients (18 males and 4 females, mean age 69 years; range 52 to 83 years) were studied during routine balloon angioplasty of the supcrficial femoral artery to treat disabling claudication. Informed consent was obtained from each patient.

The ultrasound catheter was advanced via a $7 \mathrm{~F}$ sheath into the superficial femoral artery. $\Lambda$ fter balloon dilatation, a series of cross-sectional images were recorded during pull-back of the catheter. When possible, the electrocardiogram was recorded at the same time. When interpretation of the images was difficult due to high intensity backscatter by blood, $15 \mathrm{~mL}$ of saline was injected via the sideport of the sheath. For the present study, only those sites were selected where a saline flush had been applied and where at least 26 subsequent ultrasound images from one location were available.

\section{Image analysis}

For data acquisition an IBM PC-based frame grabber $(512 \times 512$ by 8 bits) was used. Data analysis was performed with TCL-image software (Multihouse, The Netherlands).

From a set of 26 consecutive original images taken at a fixed position in the artery, the conventional ensemble average of the intensity of each pixel in the input images [eqn (1)] and the ensemble average of $25(N-1)$ consecutive subtraction images [eqn (2)] were calculated. To prevent negative intensities, the absolute value of the subtraction pixel value was taken. This resulted in the mean subtraction image and the conventionally averaged image, respectively.

$$
\begin{gathered}
\sum_{i=1}^{N} \frac{I_{i}}{N}, \\
\sum_{i=1}^{N-1} \frac{\left|I_{i+1}-I_{i}\right|}{N-1} .
\end{gathered}
$$

When the arterial segment was found to be pulsatile, only images in the interval from $\mathrm{T}$-wave to $\mathrm{R}$-wave were used.

Images were analyzed with a digital video analyzer as described previously (Wenguang et al. 1991). The free lumen area was manually traced in each mean subtraction image, conventionally averaged image and corresponding saline flush image.
With regard to the number of interruptions in the luminal wall (i.e.. dissections and/or plaque fractures), postdilatation images were analyzed independently by three observers. To avoid fragmenting the data into many categories of arterial wall injury such as "dissection," "plaque fracture" or "false lumen," the term "dissection" is used throughout this article to refer to any ultrasonographic arterial wall disruption. If discrepancies between the observers arose, agreement was reached by consensus. After analyzing the single images of each of the three methods, the real-time images were assessed (gold standard).

For each arterial cross-section, the observers determined if the extent of a dissection found at an identical location in the mean subtraction image, conventionally averaged image and saline flush image matched the real-time images, with respect to the circumference and visual differences in cross-sectional area of the dissection.

\section{Statistical analysis}

Correlation coefficients were determined to test the interobserver variability for luminal cross-sectional area measurements in 24 predilatation images.

The specificity of diagnosing a disscction by method $\mathrm{A}$ is given by ( $n=$ number of observations):

$\frac{n \text { (dissection(method A) } \cap \text { dissection (gold standard)) }}{n(\text { dissection }(\text { method A)) }}$

The sensitivity of diagnosing a dissection by method $A$ is given by:

$\underline{n \text { (no dissection(method } \mathrm{A}) \cap \text { no dissection (gold standard)) }}$ $n$ (no dissection(method $\mathrm{A})$ )

The number of "no dissections (method A)" was determined by summating the number of false negative findings for method $\mathrm{A}$ and the number of postdilatation cross-sections where method A revealed no vascular wall injury. The number of "no dissections (gold standard)" was determined by summating the number of postdilatation cross-sections where the real-time images revealed no vascular wall injury.

To compare the accuracy for each method to detect dissections, as to both location and extent, the Pearson $\chi^{2}$-test was performed. A $p<0.05$ was considered a significant difference.

\section{RESULTS}

Eighty-four sites were examined in this study, 24 obtained before and 60 obtained after balloon angi- 


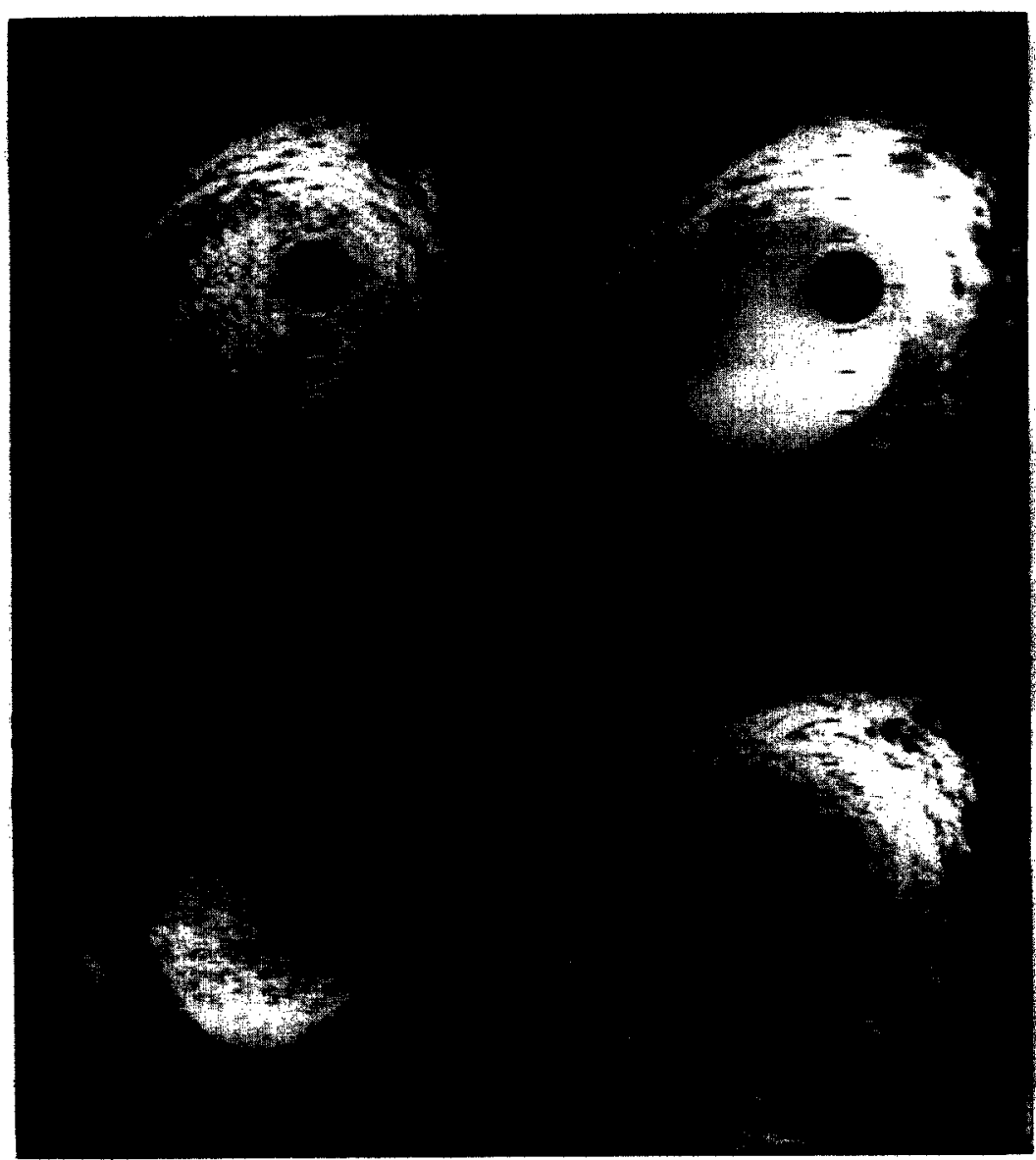

Fig. 1. Intravascular ultrasound images of the superficial femoral artery obtained following balloon angioplasty. (A) Original postdilatation image in which the lumen is hard to outline. (B) Conventionally averaged image. (C) Mean subtraction image. (D) Saline flush image.

oplasty. At all 84 sites the mean subtraction image and the conventionally averaged image enhanced discrimination between the intravascular lumen and arterial wall compared to the single original image (Fig. 1). The luminal cross-sectional area showed excellent correlation $(r=0.96)$ between the mean subtraction image or conventionally averaged image and the saline flush image (Fig. 2).

\section{Number of dissections}

The real-time images revealed that at 60 selected postdilatation cross-sections, 59 dissections were present at 43 cross-sections (one to three per site). The remaining 17 arterial cross-sections showed no evidence of wall disruption. All dissections found angiographically were confirmed by intravascular ultrasound.

The mean subtraction images, conventionally averaged images and saline flush images showed 56, 50 and 56 dissections on 43,40 and 40 sites, respectively. Forty dissections were found at an identical location in all three single images (Fig. 3). These dissections were confirmed by the real-time images. All dissections identified by the mean subtraction image were confirmed by reviewing the real-time images. Compared to the real time images, eight dissections detected by saline flush proved to be false positive observations (Figs. 3 and 4). In these cases, all three observers concluded that, with the knowledge of the real-time images, another echolucent structure had been misclassified as dissection on the saline flush image. Furthermore, the conventionally averaged image produced two false positive dissections (Figs. 3 and 4). The mean subtraction image was most consistent with the real-time images with only three false-negative observations, compared to the conventionally averaged image with 12 and the saline flush image with 11 false negative observations (Figs. 3 to 5).

The sensitivity and specificity of detecting the dissections was in the mean subtraction image $85 \%$ and $100 \%$, in the conventionally averaged image $57 \%$ and $96 \%$, and in the saline flush image $58 \%$ and $86 \%$, respectively. 

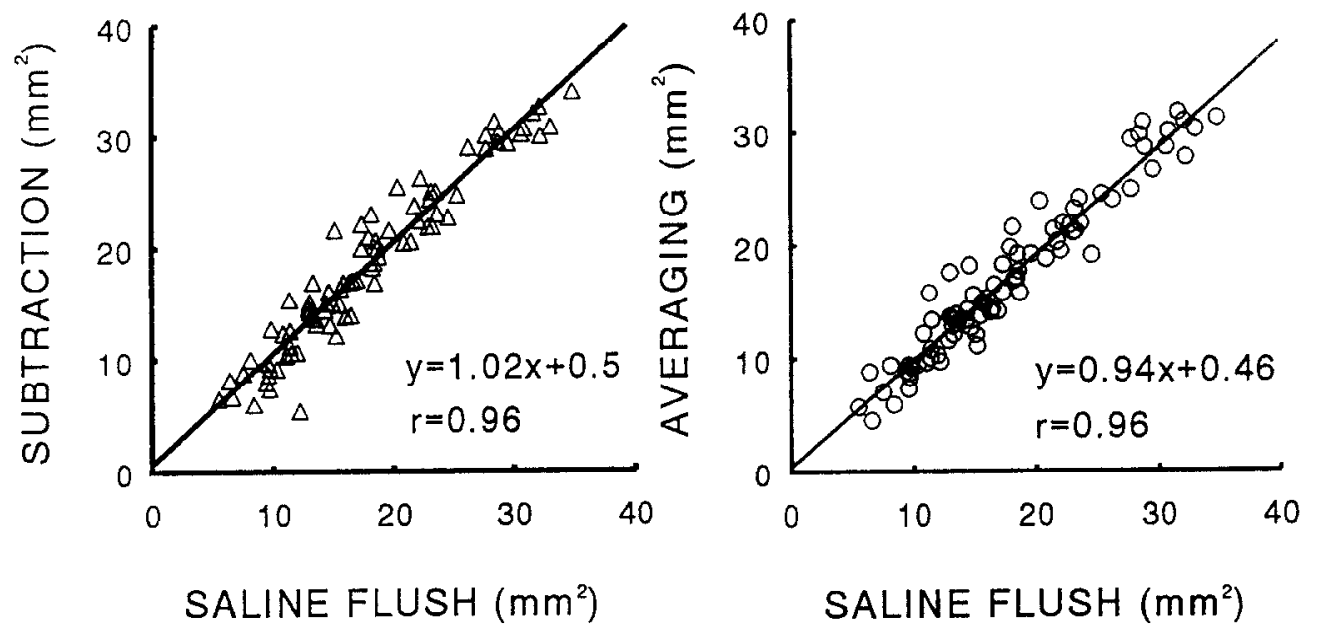

Fig. 2. Luminal cross-sectional area $\left(\mathrm{mm}^{2}\right)$ in pre- and postdilatation images $(n=84,22$ patients). Left panel: mean subtraction image vs. saline flush image. Right panel: conventionally averaged image vs. saline flush image.

\section{Extent of dissections}

Figure 6 illustrates that the extent of the dissection, in this case a false lumen, was conspicuously different for both the mean subtraction image and the conventionally averaged image compared to the saline flush image. In 11 images, all observers judged that the contour and extent of a dissection differed in one mean subtraction image, conventionally averaged image or saline flush image compared to the other two methods. The real-time images revealed that, in all 11 cases, the interpretation of the deviant image appeared to be erroneous. In the mean subtraction image and the conventionally averaged image, the cross-sectional area of the dissection was underestimated at three and two sites, respectively (Table 1). At all six sites where the saline flush image appeared to be erroneous, the

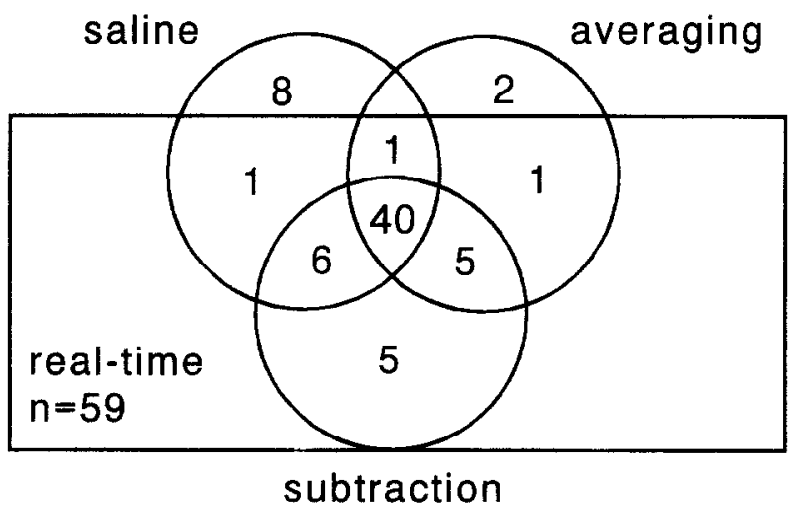

Fig. 3. Modified Venn diagram of the number of dissections identified on the real-time images, the mean subtraction image, the conventionally averaged image and the saline flush image. The mean subtraction image was most consistent with the real-time images (gold standard). cross-sectional area of the dissection was overestimated.

In summary, of the 59 dissections identified in the real-time images, on the saline flush image only 42 were accurately visualized as to both location and extent. On the conventionally averaged image 44 were accurately visualized, but on the mean subtraction image 54 of 59 dissections were accurately visualized (mean subtraction image vs. saline flush: $\chi^{2}=13.50, p$ $=0.00024$; mean subtraction image vs. conventionally averaged image: $\chi^{2}=16.02, p=0.00006$ ).

\section{Reproducibility}

All three observers evaluated $3 \times 60$ postdilatation images. They disagreed about the number and/or extent of dissections present in 32 images (18\%) (11 saline flush images, 17 conventionally averaged images, 4 mean subtraction images). After replay of the real-time images agreement was reached by consensus in all cases but one.

The interobserver variability test for luminal cross-sectional area showed an excellent correlation coefficient of $0.99(y=1.03 x-0.26)$.

\section{DISCUSSION}

Intravascular ultrasound is accepted as the best diagnostic modality to demonstrate arterial wall injury after balloon angioplasty (The et al. 1992; Yock et al. 1991; Coy et al. 1992; Tobis et al. 1989). However, with $30-\mathrm{MHz}$ IVUS imaging the confounding backscatter by red blood cells (Kallio and Alanen 1988; Heiden et al. 1991) often prevents proper identification of the intravascular lumen in single intravascular ultra- 


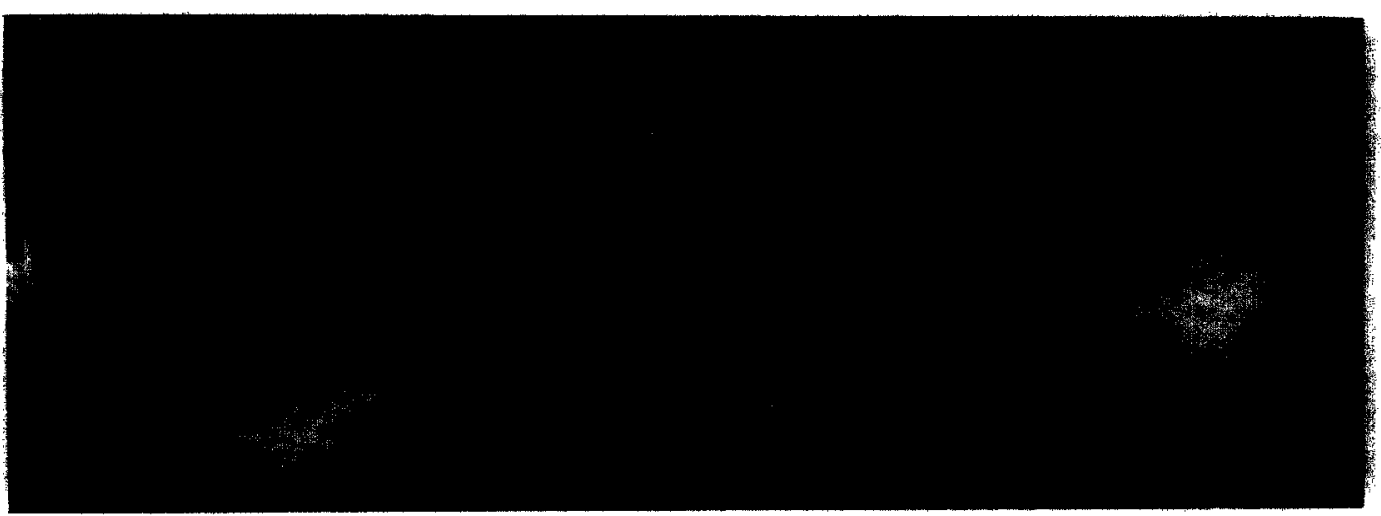

Fig. 4. Intravascular ultrasound cross-sections with conflicting findings in (A) the saline flush image, (B) the conventionally averaged image and $(C)$ the mean subtraction image. In the saline flush image (A) a dissection was identified at 2 o'clock (arrow). In the conventionally averaged image (B), a dissection was identified at 4 o'clock (arrow) because of a difference in texture. The mean subtraction image $(C)$, however, revealed a dissection at 6 o'clock (arrow). Reviewing the dynamic real-time images confirmed the presence of one dissection at 6 o'clock.

sound images employed for quantitative analysis (Pasterkamp et al. 1993).

The aim of this study was to compare three methods which improve the discrimination between lumen and arterial wall in single intravascular ultrasound images: the subtraction technique (Pasterkamp et al. (1993), conventional averaging and the use of a saline flush. Using the real-time images as gold standard, the subtraction technique was superior to conventional averaging and saline flush in detceting the number and the extent of dissections. Since the cross-sectional area of the dissections was small compared to the main lumen, the luminal cross-sectional areas in the three methods corresponded closely.

The emphasis on the proper identification of dissections after balloon angioplasty was fostered by reports that the presence of dissections may be an important predictor of early complications (Black et al.
1989; Bredlau et al. 1985; Ellis et al. 1988) or development of restenosis due to intimal proliferation (Waller et al. 1991). There is no consensus, however, on the predictive value of dissections as seen on angiography (Leimgruber et al. 1985; Bourassa et al. 1991; Leimgruber et al. 1986). At present, the sensitivity by which intravascular ultrasound can demonstrate dissections is suboptimal (Davidson et al. 1991; Coy et al. 1992; Tobis et al. 1989; Honye et al. 1992).

In a postmortem PTCA study, Potkin et al. (1988) found that a plaque tear was present in one or more histologic sections in 25 of 26 patients $(96 \%)$ with prior PTCA. Most in vivo intravascular ultrasound studies do not approximate this number of tears found after balloon angioplasty. So, intravascular ultrasound may underestimate the number of dissections caused by balloon angioplasty. This is confirmed by Görge et al. (1993) who reported that intravascular ultrasound

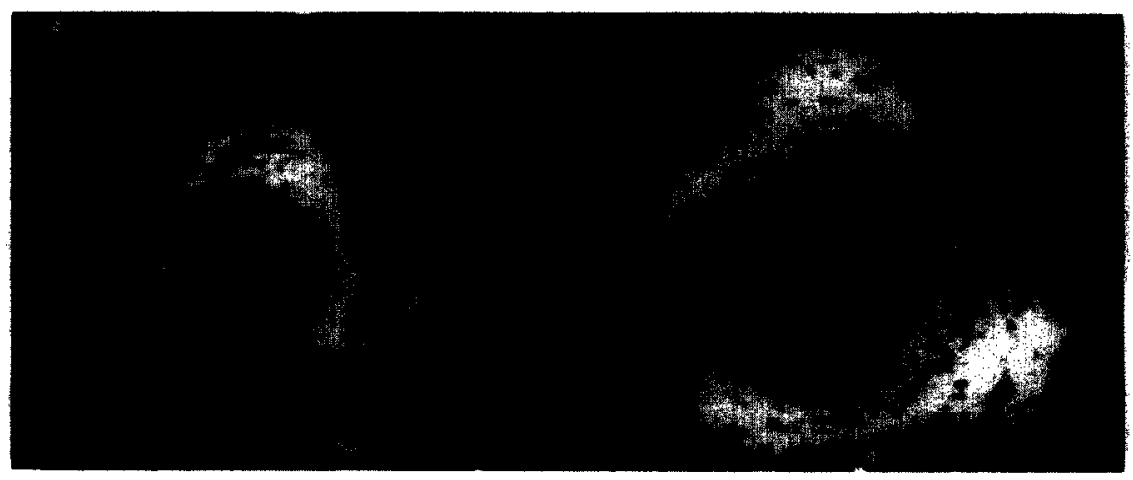

Fig. 5. Intravascular ultrasound cross-sections with a dissection found in (A) the mean subtraction image, which was not observed in (B) the saline flush image. The presence of this dissection was confirmed by watching the real-time images. 


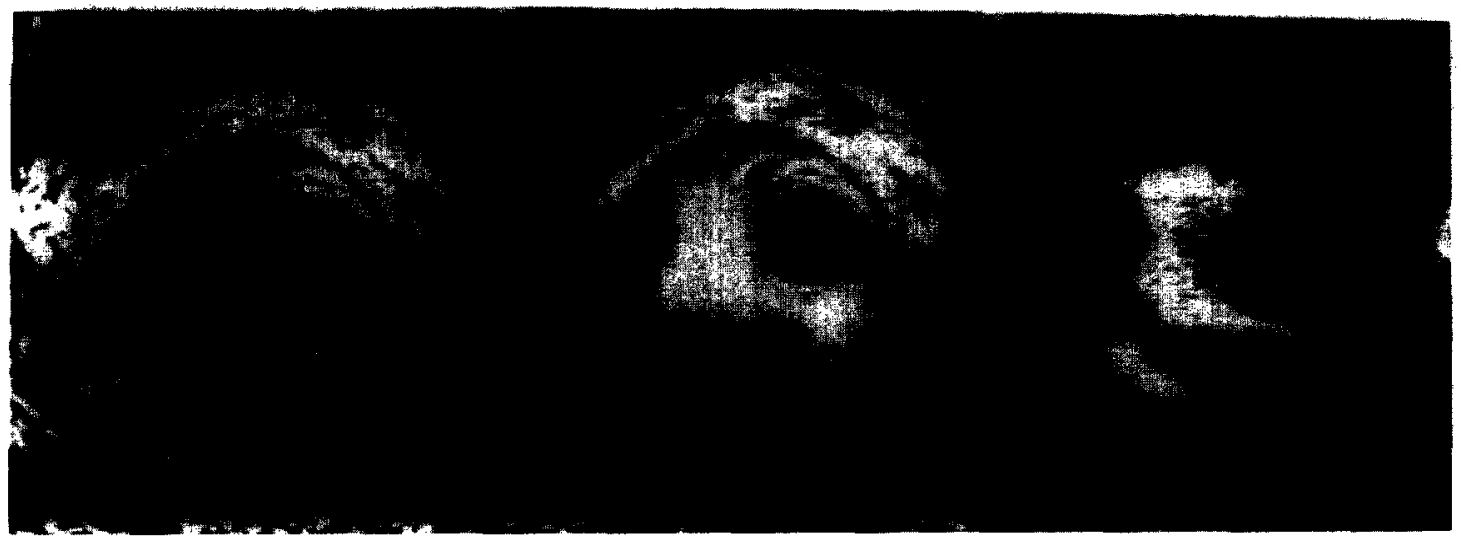

Fig. 6. Intravascular ultrasound cross-sections revealing a false lumen at 6 to 8 o'clock. The extent of the false lumen was overestimated (arrowheads) in (A) the saline flush image. compared to $(B)$ the conventionally averaged image and to $(C)$ the mean subtraction image. The real-time images confirmed the findings in the conventionally averaged image and the mean subtraction image.

misses $15 \%$ of dissections compared to angiography. This lack of sensitivity may be partly due to the catheter compressing the dissection flap against the arterial wall (Görge et al. 1993).

Theoretically, at 40 to $50 \mathrm{MHz}$ a better resolution of the arterial wall is obtained. With the subtraction technique, the associated augmented backscatter intensity of blood need not confound the proper identification of artcrial wall disruptions in single intravascular ultrasound images.

What are the reasons for misjudging dissections on saline flush images? Compared with the real-time images, in the saline flush images eight dissections out of 56 appeared to be false positives. Furthermore, in six other dissections the extent was overestimated. The origin of these echolucent structures remains unclear. There was no dropout due to calcifications because the adventitia was always present behind these regions. A potential explanation may be a tear into the media, with the echolucent media being defined as part of the lumen. However, the extent of the echolucent zone was in most cases too large to ascribe it to the media,

Table 1. Cross-sectional area of dissections.

\begin{tabular}{lccc}
\hline & Underestimated & Accurate & Overestimated \\
\hline Subtraction & 2 & 54 & 0 \\
Averaging & 3 & 44 & 0 \\
Saline flush & 0 & 42 & 6 \\
\hline
\end{tabular}

Number of intravascular ultrasound images in which all three observers judged that the extent of the dissection was underestimated, accurately visualized or overestimated in the mean subtraction images ( $n=56$ ), conventionally averaged images ( $n=$ $47)$ and saline flush images $(n=48)$. The real-time images served as gold standard. Misclassified dissections have not been included (cf. Fig. 3) especially when one considers that medial thinning is a common feature in severe atherosclerosis (Isner et al. 1986; Gussenhoven et al. 1991). An intramural thrombus is also unlikely to be responsible for the echolucency, because it appears to be uniformly speckled (Pandian et al. 1990; Frimerman et al. 1992). The presence of lipid deposits is a likely explanation as they appear echolucent (Gussenhoven et al. 1989: Potkin et al. 1985). Histologic validation remains necessary to identify these echolucent structures on saline flush images and real-time images.

The large number of false negative findings in saline flush images is another source of concern. The saline may not have reached every nook and cranny of the irregular lumen. Alternatively, the bolus injection may have altered the hemodynamics which might have obliterated a dissection. In either case, it is doubtful whether the use of sonicated solutions to enhance contrast between lumen and arterial wall (Schwarzacher et al. 1992) will overcome the problem of false negatives. In the present study, however, the low sensitivity values may have been affected by the low number of sites where no dissections were identified and may well be underestimations.

Subtraction is an established method to discriminate a few varying elements in two virtually identical images (Ziedses des Plantes 1935). This study illustrates that the application of the subtraction technique may also be of use in ultrasonography to discriminate be tween static and dynamic scenes. In the present study blood itself acted as contrast by subtracting subsequent images. To date, the saline flush image is considered the gold standard for quantitative intravascular ultrasound measurements of the arterial lumen in single images. This study suggests that the saline flush image is not a 
proper gold standard among the single images compared to the real-time images. The mean subtraction image was more accurate than the saline flush image in detecting dissections as small extensions of the intravascular lumen or as false lumina. Therefore, the mean subtraction image is a potential gold standard to delineate the irregular lumen following balloon angioplasty in a single image. The intravascular lumen can be quantitatively analysed in the mean subtraction image without the need to replay the video-tape several times.

In principle, real-time implementation of the subtraction method may allow automated segmentation of the lumen which is necessary for on line quantitative measurement of the luminal cross-sectional area or for three-dimensional visualization (Coy et al. 1992; Klein et al. 1992).

In a pulsatile artery the moving vessel wall and moving intimal flaps will partly fail to cancel out by subtraction. Electrocardiogram-triggered image acquisition may produce the same result as in a nonpulsatile arterial site as shown in Fig. 1. However, this requires an extended acquisition period. If blood flow stagnates in a dissection, the dissection may be missed by the subtraction method. In the mean subtraction image, valuable information about the morphology of the arterial wall is lost. Superimposing the lumen identified on the mean subtraction image on an original image may therefore be an attractive method to visualize both the intravascular lumen and the vessel wall in single images. Another limitation of this study is that the presence or extent were not scored in a blinded fashion. This may be a potential source of bias in the experimental design.

In conclusion, the subtraction method provides one single intravascular ultrasound image with a sharp demarcation between lumen and arterial wall without the necessity to flush. Compared to real-time images, the mean subtraction image was more accurate in detecting dissections than the conventionally averaged image and even the saline flush image.

Acknowledgements - G. P. was supported by The Netherlands Heart Foundation (Grant 92,136).

\section{REFERENCES}

Black, A. J. R.; Namay, D. L.; Niederman, A. L.; Lembo, N. J.; Roubin, G. S.; Douglas, J. S., Jr.; King III, S. B. Tear or dissection after coronary angioplasty. Circulation 79:1035-1042; 1989.

Bourassa, M. G.; Lesperance, J.; Eastwood, C.; Schwartz, L.; Côté, G.; Kazim, F.; Hudon, G. Clinical, physiologic, anatomic and procedural factors predictive of restenosis after percutaneous transluminal angioplasty. J. Am. Coll. Cardiol. 18:368-376; 1991.

Bredlau, C. E.; Roubin, G. S.; Leimgruber, P. P.; Douglas, J. S., Jr.; King III, S. B.; Gruentzig, A. R. In-hospital morbidity and mortality in patients undergoing elective coronary angioplasty. Circulation 72:1044-1052; 1985.
Coy, K. M.; Park, J. C.; Fishbein, M. C.; Laas, T.; Diamond, G. A.; Adler, L.; Maurer, G.; Siegel, R. J. In vitro validation of three dimensional intravascular ultrasound for the evaluation of arterial injury after balloon angioplasty. J. Am. Coll. Cardiol. 20:692$700 ; 1992$.

Davidson, C. J.; Sheikh, K. H.; Kisslo, K. B.; Philips, H. R.; Peter, H.; Behar, V. S.; Kong, Y.; Krucoff, M.; Magnus, Ohman, E.; Tcheng, J. E.; Stack, R. S. Intracoronary ultrasound evaluation of interventional techniques. Am. J. Cardiol. 68:1305-1309; 1991.

Ellis, S. G.; Roubin, G. S.; King III, S. B.; Douglas, J. S., Jr.; Weintraub, W. S.; Thomas, R. G.; Cox, W. R. Angiographic and clinical predictors of acute closure after native vessel coronary angioplasty. Circulation 77:372-379; 1988.

Frimerman, A.; Miller, H. I.; Laniado, S.; Keren, G. Intravascular ultrasound of thrombi of different composition: an in vitro study [abstract]. Circulation 86(suppl. I):2293; 1992.

Görge, G.; Erbel, R.; Gerber, T.; Ge, J.; Kearney, P.; Rupprecht, H. J.; Meyer, J. Dissections after PTCA: Comparison angiography-intravascular ultrasound. Eur. Heart J. 14(suppl.):366; 1993.

Gussenhoven, E. J.; Essed, C. E.; Lancée, C. T.: Mastik, F.: Frietman, P.; van Egmond, F. C.; Reiber, J.; Bosch, H.; van Urk, H.; Roelandt, J.; Bom, N. Arterial wall characteristics determined by intravascular ultrasound imaging: An in vitro study. J. Am. Coll. Cardiol. 14:947-952; 1989.

Gussenhoven, E. J.; Frietman, P. A. V.; The, S. H. K.; van Suylen, R. J.; van Egmond, F. C.; Lancée, C. T.; van Urk. H.; Roelandt, J. R. T. C.; Stijnen, T.; Bom, N. Assessment of medial thinning in atherosclerosis by intravascular ultrasound. Am. J. Cardiol. $68: 1625-1632 ; 1991$.

van der Heiden, M. S.; de Kroon, M. G.; Savalle, L. H.; Borst, C. Backscatter of $30 \mathrm{MHz}$ ultrasound by human hlood is caused by red blood cells and enhanced by rouleaux formation [abstract]. Circulation 84 (suppl. II):614; 1991.

Honyc, J.; Mahon, D. J.; Jain, A.; White. C. J.; Ramee, S. R.; Wallis, J. B.; Al-Zarka, A.; Tobis, J. M. Morphological effects of coronary balloon angioplasty in vivo assessed by intravascular ultrasound imaging. Circulation 85: 1012-1025; 1992.

Isner, J. M.; Donaldson, R. F.; Fortin, A. H.; Tischler, A.; Clarke, R. H. Attenuation of the media of coronary arteries in advanced atherosclerosis. Am. J. Cardiol. 58:937-939; 1986.

Isner, J. M.; Rosenfield, K.; Losordo, D. W.; Rose, L.; Langevin. R. E., Jr.; Razvi, S.; Kosowsky, B. D. Combination balloonultrasound imaging catheter for percutaneous transluminal angioplasty. Circulation 84:739-754; 1991.

Kallio, T.; Alanen, A. A new ultrasonic technique for quantifying blood echogenicity. Invest. Radiol. 23:832-835; 1988.

Klein, H. M.; Gunther, R. W.; Verlande, M.; Schneider, W.; Vorwerk, D.; Kelch, J.; Hamm, M. 3D surface reconstruction of intravascular ultrasound images using personal computer hardware and a motorized catheter control. Cardiovasc. Interv. Radiol. 15:97-101; 1992.

Leimgruber, P. P.; Roubin, G. S.; Anderson, H. V.; Bredlau. C. E.; Whithworth, H. B.; Douglas, J. S., Jr.; King III, S. B.; Gruentzig, A. R. Influence of intimal dissection on restenosis after successful coronary angioplasty. Circulation $72: 530-535 ; 1985$.

Leimgruber, P. P.; Roubin, G. S.; Hollman, J.; Cotsonis, G. A.; Meier, B.; Douglas, J. S.; King III, S. B.; Gruentzig, A. R. Restenosis after successful coronary angioplasty in patients with single vessel disease. Circulation 73:710-717; 1986.

Pandian, N. G.; Kreis, A.; Brockway, B. Detection of intraarterial thrombus by intravascular high frequency two-dimensional ultrasound imaging in vitro and in vivo studies. Am. J. Cardiol. $65: 1280-1283 ; 1990$.

Pasterkamp, G.; van der Heiden, M. S.; Post, M. J.; Ter Haar Romeny, B.; Mali, W. P. T. M.; Borst, C. Turning 'confounding' backscatter of blood at $30 \mathrm{MHz}$ intravascular ultrasound into an advantage: A new method to discriminate intravascular lumen and dissections in a single image. Radiology 187:871 -872; 1993.

Potkin, B. N.; Roberts, W. C. Effects of percutaneous transluminal coronary angioplasty on atherosclerotic plaques and relation of plaque composition and arterial size to outcome. Am. J. Cardiol. 62:41-50, 1988. 
Potkin, B. N.; Bartorelli, A. L.; Gessert, J. M.: Neville, R. F.: Almagor. Y.; Roberts, W. C.: Leon, M. B. Coronary artery imaging with intravascular high frequency ultrasound. Circulation $81: 1575-1585 ; 1990$

Schwarzacher, S.; Weidinger, F.; Gabriel, H.: Zangeneh, M.; Glogar, D. Enhanced visualization of the coronary intimal layer by ultrasound using echodense contrast medium [abstract]. Circulation 86(suppl. I): 1289; 1992.

The. S. H. K.; Gussenhoven, E. J.: Zhong, Y.: Li, W.; van Egmond, F.: Pieterman, H.; Urk van, H.: Gerritsen, G. P.; Borst, C.: Wilson. R. A.; Bom, N. The effect of balloon angioplasty on the femoral artery evaluated with intravascular ultrasound imaging. Circulation 86:483-493; 1992.

Tobis, J. M.; Mallery, J. A.; Gessert, J.; Griffith, J.; Mahon. D.; Bessen, M.; Moriuchi, M.; McLeay, L.: McRae, M.; Henry, W. L. Intravascular ultrasound cross-sectional arterial imaging before and after balloon angioplasty in vitro. Circulation 80:873882: 1989.
Waller. B. F.; Pinkerton, C. A.; Orr, C. M.; Slack, J. D.; VanTassel, J. W.; Peters, T. Morphological observations late $(>30$ days) after clinically successful coronary balloon angioplasty. Circula tion 83:128-141: 1991

Waller, B. F.; Pinkerton, C. A.; Slack, J. D. Intravascular ultrasound A study of vessels during life. The new 'gold standard' for vascular imaging. Circulation 85:2305-2310: 1992

Wenguang, L.; Gussenhoven, E. J.; Zhong, Y.; The, S. H. K.; Di Mario, C.; Madretsma, S., van Egmond, F.; de Feyter, P.; Pieter man, $\mathrm{H}$; van Urk, $\mathrm{H}$; Rijsterborgh, $\mathrm{H}$;; Bom, N. Validation of quantitative analysis of intravascular ultrasound images. Int. I Cardiol. Imag. 6:247-253; 1991.

Yock, P. G.; Fitzgerald, P. J.: Linker, D. T.: Angelsen, B. A. J Intravascular ultrasound guidance for catheter-based coronary interventions. J. Am. Coll. Cardiol. 17:39B-45B; 1991.

Ziedses des Plantes, B. G. Eine Röntgenographische Methode zur separaten Abbildung bestimmter Teile des Objects. Fortschr. Röntgenstr. 52:69; 1935 . 